\title{
Scientific Research Studies in Yoga: Some Lapses of Fundamental Nature
}

\author{
Mukund Vinayak Bhole* \\ Consultant in Yoga Therapy, Lokmanya Medical Research Centre, India
}

Submission: June 18, 2019; Published: November 13, 2019

*Corresponding author: Mukund Vinayak Bhole, 16 Badrivishal Society, Tungarli, P.0.-Kaivalyadhama, Lonavala (Dist.-Pune), Maharashtra 410403, India Email:mv35bhole@gmail.com

Abstract

In 2003, the World Health Organization decided to collect reliable information on Traditional, Complementary and Alternative Medicine (TM and CAM) from its member states to promote proper use of these systems for consumers and health providers. 'Traditional Yoga' developed in ancient India and mostly practiced for 'Self-realization' was also included in this category. The WHO (South-East Asia) in co-operation with the M.D. National Institute of Yoga, Ministry of AYUSH, Govt. of India developed technical guidelines and information on Yoga to help and ensure the safety of consumers and health providers. These guidelines were approved in the WHO Consultation Meeting held in New Delhi.

Keywords: Yoga; Preventive; Yoga therapy; Yoga techniques; Body-mind work

\section{Introduction}

In recent times, there is a global interest in using 'Yoga' as preventive, promotional and palliative health care adjunct. There is a growing trend amongst patients to take a more proactive approach to their own health and to seek out different forms of self-care measures, including 'Yoga'. In addition to the many benefits of 'Yoga', recent reports have shown that there are also risks associated with the different types of Yoga employed as 'Yoga Therapy' (TM/CAM). Although consumers today have widespread access to various Yogic practices used as treatments and therapies, they often do not have enough and proper information on where, how and what to find and check the reliability and correctness of various Yoga techniques and protocols used in Yoga therapy.

\section{Scientific research in yoga and yoga therapy}

'Yoga practices' are being applied in the management of various clinical conditions. Most of these studies indicate application of 'Yoga intervention' for patients (human population) i.e. phase four of accepted protocol in medical research. Study of various research articles published in peer reviewed indexed journals are seen to miss or omit the following type of information which is usually carried out in the first and second phase of medical research:

a) Proper standardization and validation of different Yoga techniques or practices used as intervention in Yoga Therapy. b) Validation and verification of the expected outcome of each Yoga technique used as intervention in Yoga Therapy.

c) Recognition, confirmation and quantitative and/or qualitative measurement/s of the expected outcome of the Yoga technique/s by the experimenter and/or the patient.

d) Recognition, confirmation and measurement of the unwanted or negative effects of the Yoga techniques employed as interventional practices.

e) The basis of deciding the time duration of each Yoga technique (comparable to the Dose of medicine) and the foundations used for deciding this basis or only empirical basis is used.

f) In what way or manner, the patients experience and/or recognize various parameters used for objective study by the experimenter?

g) Will the practitioner/patient of Yoga will be able to get guided by various parameters used for study or the patient will have to depend on laboratory studies and how far?

Generally, these are the areas of work expected to be studied during first and second phase of studies before applying the desired interventions on human/patient population. It appears that almost negligible number of investigators working in the field of Yoga are interested and want to take interest in this fundamental research studies. 


\section{Types of Misguiding and Misleading Statements}

Various statements are being made in respect of Yoga by the Yoga experts and scientific workers. Some examples are given below:

\section{Yoga is body-mind work}

Almost all the training and educational programs involving conscious human beings involve 'Body-Mind' work. For example, learning to sit, stand, walk, swallowing food, drinking water as a child; learning to memorize alphabets, playing games, working with computers, etc. require body-mind work. In Yoga, techniques such as mental recitation of 'Mantras' and experiencing transcendental states of consciousness are mostly 'mental activities' where participation of the physical body is mostly unconscious in nature. Therefore, presenting Yoga as 'Body-Mind work' serves as misguiding and misleading statement for the beginners in Yoga as well as for the ignorant people.

\section{Yoga is mindfulness}

Jon Kabat-Zinn says, "Mindfulness means paying attention in a particular way; on purpose, in the present moment, and nonjudgmentally." Usually the minds of most of the people are 'full' of something or the other, even during sleep. To empty the mind and to keep it empty for some time is a real achievement which is not very easy to achieve and maintain. The important thing is to highlight and streamline the exact nature of 'mindfulness' as has been highlighted by Ekhart Yoga by mentioning sound, body sensations and breath as 'anchors' during Yoga practice. Generally, this is not mentioned nor explained in details in clearcut language and the methods used to attain and confirm the same $[6,7]$.

\section{'Inhalation' is "pūraka" and 'exhalation' is "rechaka"}

Traditional Yoga texts mention about experiencing the trunk area having an internal space or a cavity (e.g. pelvic cavity, abdominal cavity and thoracic cavity in medical sciences). Experiencing these spaces or cavities getting filled as 'Pūraka' and 'the spaces getting emptied as 'Rechaka'. The direction of the internal movement during 'filling phase' (pūraka) related with 'inhalation' is from 'below $\rightarrow$ up' and from 'above $\rightarrow$ down' during the 'emptying phase' related with exhalation. The movement of breath perceived through the touch of air movement inside the nostrils and the mouth during 'inhalation' (svāsa in Yoga) is from 'above $\rightarrow$ down' and from 'below $\rightarrow$ up' during exhalation (prasvāsa in Yoga). Thus the experiential aspects of 'inhalation/pūraka' and 'exhalation/rechaka' are opposite in nature. Therefore, these terms cannot be used as synonyms as is being done presently [8].

\section{"Oxygen is "prāna vāyu" and carbon-di-oxide is "apāna vāyu"}

\section{"Chakrās" (Wheels) and "Lotuses" are synonyms}

Likewise, the scientific and the Yoga worlds are seen to use
'Oxygen gas' and 'prāna vāyu' of Yoga and 'Carbon-di-oxide gas' and 'apāna vāyu' of yoga as synonyms. Detailed analysis of the terms, 'prāna vāyu' of Yoga imply gross voluntary as well as involuntary movements of the body (pyscho-physical and neuromuscular actions and activities) responsible for taking in or receiving air, water, food because of the expanding movements of the trunk and internal organs while 'apāna vāyu' being the retracting movements of the body responsible for evacuation and expulsion of materials from the body (exhalation, micturition, defecation, etc.). These two 'vāyus' belong to a group of 'ten vāyus' mentioned in yoga texts, subjectively experienced by the person/patient in an intact body. On the other hand, 'lotuses' and 'chakrās' are the descriptions of certain types of subjectively experienced happenings taking place inside the body after some suitable Yoga practices $[9,10]$. 'Lotus flower like expansion and retraction' of the trunk can be experienced by placing our hands over the sides of the trunk at different levels. In Yoga, after suitable practices, such movements can be subjectively experienced at the level of the

i. Perineum,

ii. Pelvis,

iii. Stomach,

iv. Chest,

v. Neck

vi. The forehead in relation to breathing during the practice of 'prānāyāma'.

At the level of the mind, various feelings, thoughts and behaviors can give rise to conflicting and whirlpool like state of consciousness keeping the person under stress and tensions all the time requiring medical guidance and help. In a very practical way, the concept of "Lotuses" can be understood in terms of the gross body movement related with breathing subjectively experienced and recognized by the person in the region of the trunk, neck and head and the concept of "Chakrās" as the functional state of the mind as subjectively experienced and recognized by the person.

We come across two technical terms in Yoga literature:

a) 'Lotuses'

b) 'Chakrās'.

\section{Lotuses}

'Lotuses' are 'flowers' belonging to the vegetable kingdom in the Nature. The plant grows from a bulb and survives in water. There can be a number of lotus plants in a pond or a lake and the lotuses can remain at different levels over the surface of the water connected by its stalk with the bulb at the bottom of the pond. Lotuses have a 'stalk', 'calyx' and 'petals' like any other flowers. Lotuses open around sunrise, remain open throughout the day and start closing around sunset and remain in a closed 
condition (like a bud) throughout the night. This movement takes place in horizontal plane.

\section{Chakrās}

'Chakrās' (wheels or circular discs moving around their axis) are made by man using different materials such as wood, stone, metals, plastic, etc. They have 'spokes' connecting the periphery with the central hub serving as an axis around which the wheel moves in different planes: vertical, horizontal or even oblique plane on the ground, in air or water. The movement can be in a clockwise or anti-clockwise direction with different speeds.

Modern authors (including well qualified medical men) are using 'lotuses' and 'chakrās' as synonyms and making a statement that 'Chakras' have 'petals. They are even trying to equate them both with different nerve plexuses and endocrine glands. Nerve plexuses and endocrine glands are anatomical structures. These structures and their functions cannot be $[11,12]$.

\section{Conclusion}

It can be said that research studies of more fundamental nature are required to be undertaken by the scientific community to have clear understanding about the exact nature of the Yoga techniques employed as interventions in therapy or health care. Levine AS and Balk JL have come to the similar conclusion by declaring that, 'although participation in yoga programs appeared to benefit patients with breast cancer, greater methodological rigor is required to understand the mechanisms that contribute to their effectiveness.' Field $\mathrm{T}$ has opined in a similar way by reporting, 'Multiple physical and physiological measures need to be added to the self-report research protocols and potential underlying mechanisms need to be further explored. In the interim, the studies reviewed here highlight the therapeutic effects of yoga, a practice that could come to be called yoga therapy.

\section{References}

1. (2014) WHO Consultation Meeting held in New Delhi.

2. Can yoga be dangerous? - Health \& Wellbeing - ABC

3. https://www.abc.net.au/health/talkinghealth/factbuster/stories/2013/05/02/3750102.htm

4. ALERT: Ways yoga can harm you - Times of India

5. https://timesofindia.indiatimes.com/life-style/health-fitness/fitness/ALERT-Ways-yoga-can-harm-you/articleshow/46878232.cms

6. https://nccih.nih.gov/health/yoga

7. Yoga is a mind and body practice with origins in ancient Indian philosophy.

8. https://www.ekhartyoga.com/articles/practice/what-is-mindfulness

9. (2005) Siddha-siddhanta-paddhati' of Gorakshanath. In: Gharote ML, Pai GK, (Edt.), Published by Lonavala Yoga Institute, Lonavala, India, p. 23-24.PTER-!, H

10. (1999) Shiva Samhita (in Hindi). In: Swami Maheshananda, Sharma BR, Sahai GS, Bodhe R, (Edt.), Published by Kaivalyadhama SMYM Samiti, Loavala, India, p. 98-99.

11. (2004) 'Chakrās - Wheels of life' by Anodea Judith, Jaico Publishing House, Mumbai, India.

12. (2018) Yoga as Therapy - Medical view, Practical guide for health and diseases. By Satish Pathak. Published from Kaivalyadhama S.M.Y.M. Samiti, Lonavala, India, pp. 113-120.

\section{Your next submission with Juniper Publishers will reach you the below assets}

- Quality Editorial service

- Swift Peer Review

- Reprints availability

- E-prints Service

- Manuscript Podcast for convenient understanding

- Global attainment for your research

- Manuscript accessibility in different formats

( Pdf, E-pub, Full Text, Audio)

- Unceasing customer service

Track the below URL for one-step submission

https://juniperpublishers.com/online-submission.php 